The Labore Journal of Economics

Special Edition

\title{
Investment in Education and Skill Development
}

\section{Sartaj Aziz ${ }^{*}$}

"Pakistan's investment in its people today not only falls below any decent concept of national governance; we are simply not preparing the nation for technological challenges of the 21st century. Where do we start in such a wasteland of human neglect? The situation cannot be reversed overnight. It would require considerable investment in human development over a fairly long period of time." Dr. Mahbubu1 Haq:

A National Agenda: Critical Choices for Pakistan's Future: 1993

According to the traditional view in the development debate of the 1960s, land, labor and capital were identified as the main factors of production and within these the focus was on expanding capital by increasing investment to at least 15 percent of GDP to achieve a growth rate of at least 5 percent.

By the early 1970s, however, the definition of capital was broadened to include human capital. Investment in education, it was pointed out on the basis of several studies, created better skills and together with research for improved technology, would lead to higher productivity and faster economic growth. The economic rationale for investment in education was thus well established by the early 1980 s.

The launch of the Human Development Report by UNDP in 1990 was another landmark in the conceptual framework for development. Pioneered by late Dr. Mahbubul Haq, the Report prescribed a supplementary criteria for determining performance called the Human Development Index (HDI). The Index builds on four indicators: life expectancy at birth, adult literacy rate, combined primary, secondary and tertiary gross enrolment ratio and GDP per capita, assigned a maximum value of 1 , on the basis of which countries are categorized into High (above 0.8), Medium (between 0.5 and 0.8) and Low HDI (below 0.5). This concept

\footnotetext{
* Vice Chancellor, Beaconhouse National University, Lahore
} 
"put people at the very centre of development" and emphasized that human development was not just a means to more rapid economic growth but also an end in its own right, as it provided "human security to all the people everywhere in their homes, in their jobs, in their communities and in their environment".

The transition of the world towards a knowledge based economy and growing competition in the wake of globalization has further magnified the importance of human resources in general and of education in particular as a key element in the process of social and economic transformation. Key indicators of progress in the coming decades will not only include the overall level of literacy, but also the proportion of skilled workers in the total work force, the percentage labor force employed in different sub sectors of communications and the investment being made in research and technology. Only societies which have acquired the required knowledge and skills will be able to compete in the global markets.

\section{The State of Education in Pakistan}

Viewed in this context, Pakistan has a long way to go. The facts and main indicators are well known, but the following shortcomings and lags are particularly noteworthy:

- Overall investment in education in Pakistan is still very low, despite repeated commitments by successive governments to reach the UNESCO target of 4 percent of GDP. Public spending on education in Pakistan, as a percentage of GDP is only 1.8 percent which is the lowest in South Asia ${ }^{1}$ and has in fact declined from the peak of 2.6 percent reached in the early 1990s.

- Because of a combination of high population growth and low expenditure on education, the average level of adult literacy has moved very slowly from 26 percent in 1981 to an estimated 54 percent in 2004. If this average is broken down between urban and rural areas, between males and females and between different provinces, the wide disparities reflected in the dismal averages becomes even more glaring. The rate of literacy for rural females in 2001-02 was only 7 percent in Balochistan, 11 percent in Sindh, 13

\footnotetext{
${ }^{1}$ Several Asian countries had already exceeded by the year 2000 the UNESCO target of $4 \%$ of GDP. India (4.1\%), Philippines (4.2\%), Iran (4.4\%), Thailand (5.4\%), Malaysia $(6.2 \%)$.
} 
percent in NWFP and 22 percent in Punjab, yielding a national average of 18 percent for female literacy. With this level of female literacy, the program for population control will have only limited chances of success because according to recent research, the fertility rate is almost 4.74 for illiterate women and 3.14 for women with tertiary education.

- Despite a three fold increase in Pakistan's GDP over the last 30 years, there has been no corresponding improvement in social indicators. Pakistan was 144th on the global ranking of the Human Development Index for 2001 among 175 countries. Pakistan and Nepal are now the only two Asian countries among 34 countries categorized with low human development index. The remaining 32 are all least developed African countries.

- Moving from the quantitative to the qualitative aspects of human development, the situation is even more depressing. On UNDP's Technology Achievement Index based on indicators like enrolment of science students, patents and royalties, and access to telephones, internet and electricity, Pakistan's rank is 0.16 , compared to 0.20 for India and Sri Lanka, 0.31 for Brazil, 0.39 for Malaysia and 0.66 for South Korea.

- Similarly on the global Knowledge Economy Index based on information, infrastructure, economic incentives regime, expenditure on research and the other indicators of human development, Pakistan's rank is 1.36, compared to 2.07 for India, 3.11 for China, 3.36 for Sri Lanka, 4.11 for Brazil, and 4.72 for Malaysia.

It should be clear from the foregoing that a very major effort will be needed on several fronts if Pakistan is to improve not only its overall level of literacy but also its ranking on the Human Development Index (HDI), the Technology Achievement Index (TAI) and the Knowledge Economy Index (KEI). The focus of these wide ranging efforts should be: (a) Mobilizing additional resources for investment in education and skill development, (b) paying greater attention to quality of education, (c) ensuring more effective implementation of educational reforms and plans through institutional and administrative improvements.

In the past few years, the Higher Education Commission and the Provincial Governments have taken many important initiatives in the field of education but there are many structural problems and institutional obstacles that have affected the implementation of well meaning policies and plans in 
the past $^{2}$. Unless these obstacles are effectively tackled, the new plans and reforms will not yield the expected results and targets. Four such problem areas and obstacles are discussed in this paper.

\section{Shrinking Fiscal Space in the Provinces}

Under the Constitution, education is a provincial subject and 90 percent of all public expenditures in the Education sector are incurred by the Provinces, but the Provinces depend primarily on Federal grants and resource transfers to finance these expenditures.

In the past 15 years, the fiscal space provided to the Provinces under successive NFC Awards has been shrinking and as a result the average growth in real development and recurring expenditures has declined progressively from 1989 onwards, as shown in the following table:

Average Growth in Real Expenditure on Education (\%)

\begin{tabular}{cccc}
\hline Years & $\begin{array}{c}\text { Total } \\
\text { Expenditure }\end{array}$ & $\begin{array}{c}\text { Development } \\
\text { Expenditure }\end{array}$ & $\begin{array}{c}\text { Recurring } \\
\text { Expenditure }\end{array}$ \\
\hline $1975-85$ & 9.95 & 11.89 & 9.98 \\
$1986-89$ & 11.81 & 17.01 & 11.73 \\
$1990-96$ & 5.91 & 4.79 & 6.65 \\
$1997-02$ & -0.90 & -10.83 & 0.56 \\
\hline
\end{tabular}

Source: Federal Budget in Brief and Provincial Annual Budget Statements (various issues)

${ }^{2}$ Apart from education plans, policies and targets identified in eight five year Plans between 1995 and 1998, there have been at least 12 comprehensive national education policies and programs:

1. National Plan of Education Development, 1951-57

2. Report of the Commission on National Education, 1959

3. New Education Policy, 1970

4. The Education Policy, 1972-80

5. National Education Policy and Implementation Program, 1979

6. Literacy and Mass Education Commission, 1981

7. 10 Point Program, 1983

8. National Literacy Plan 1984-86

9. Nation-wide Literacy Program, 1986-90

10. National Education Policy, 1992

11. National Education Policy, 1998-2010

12. Education Sector Reforms Action Plan 2001 -05 
After the first NFC Award in 1974, provinces received additional resources and were able to increase development expenditures by 12 percent and recurrent expenditures by 10 percent per annum in real terms in the period 1975-85. This trend received a boost in 1986, with Prime Minister Junejo's Five Point Program as the rate of annual increase jumped to 17 percent for development expenditures and 12 percent for recurrent expenditure during 1986-89. With the 1991 NFC Award, these growth rates slowed down to 5 percent and 7 percent respectively, as the practice of covering the budget deficits of the Provinces was discontinued and the provinces were asked to limit non-development expenditures to available resources.

Under the 1997 Award, the squeeze on provincial resources became tighter as the provinces were asked to finance even their respective development expenditures from their own surpluses and the safeguard provided in the 1991 NFC Award to cover the provincial component of PSDP was deleted. In addition, all the taxes including purely federal taxes such as customs duties were included in the divisible pool with a 62.5:37.5 percent distribution between the centre and the provinces. As the proceeds of customs duties declined as a result of the structural adjustment programs, the provinces had to share one third of this decline and received only one third of the substantial increase in Sales Tax revenues, instead of 80 percent under the 1991 formula.

With some increase in revenues, following accelerated inflows of foreign assistance and remittances after 9/11, the share of the provinces in the divisible pool (excluding special grants and electricity profits) has increased from Rs. 190 billion in 2001-02 to Rs. 240 billion in 2004-05 but this increase in educational expenditures has barely kept pace with the rate of inflation. According to official figures, total expenditure on education, in real terms, is still below 1.8 percent of GDP in 2004-05.

The most daunting challenge before the economic managers of Pakistan is finding ways and means of raising total expenditures on education to 4 percent of GDP and ensuring meaningful utilization of these resources, to achieve universal literacy in the shortest possible time, to improve the quality of education, and vastly expand opportunities for technical and vocational education.

In this context, the National Finance Commission might earmark a minimum percentage of resource transfer from the Divisible Pool, for education. At present there is a deadlock over the percentage of the Divisible Pool that will go to provinces which are demanding at least 50 
percent against the offer of 47.5 percent from the Federal Government. It will be in the longer term national interest to accept the provincial demand on the condition that the additional 2.5 percent (or Rs.14 billion in 2004$05)$ will be allocated exclusively to the education sector by the Provincial Governments. Allocation of larger financial resources for education though necessary, is not however sufficient for providing quality education to all. Ways must be found to utilize the resources wisely, cost effectively and for the right priorities.

The role of the private sector in the field of education has been expanding and according to one estimate, the private sector now provides about one third of all educational facilities in the country. This is to be welcomed. But education is a public good and must be provided by the government to all its citizens without discrimination and particularly to those who cannot afford the relatively higher fees charged by the private educational institutions.

\section{Reform of educational administration}

One of the most important lessons of successful development experience in other countries is the sequencing of various reforms. Economic and sectoral reforms have yielded positive results only when these were preceded by administrative and institutional reforms that ensured adequate implementation. In Pakistan, most of the educational reforms, action programs or initiatives have floundered because the bureaucratic structures responsible for their implementation were totally inadequate. An important example of this mis-match was the Social Action Program launched in 1992 with substantial support from external donors. Allocations for primary education under this program were doubled over the next five years, but on the average only about half the physical and qualitative targets of programs were achieved. Total enrolment increased from 11 to 19 million between 1990 and 2000, and the literacy improved from 36 percent in 1991-92 to only 47 percent in 19902000. Successive evaluations of the program showed serious inadequacies in its implementation. One such evaluation showed that as a result of frequent transfers, the average tenure of the Secretary in the Education Department of Punjab (with primary responsibility for the program and for a system employing 350,000 teachers) was less than a year. There were also reports about the appointment and transfers of teachers on the basis of political patronage, absence of incentives for good teachers and weak enforcement mechanisms for ensuring discipline and quality of service delivery. The general attitude and mindset of the provincial and local bureaucracy was also reported to be negative and not conducive to a merit based system. As a result of these assessments, this landmark program was discontinued in 2002. 
The institutional and administrative weaknesses of the education system, mentioned above, have not however disappeared. Unless these are remedied, other reforms can meet the same fate. Increased allocations can be readily spent by building physical structures through contractors, but the physical and qualitative targets in terms of actual enrolment, the quality of education and more diversified education according to future needs, will remain illusive.

Institutional reforms have to move in two directions: major decentralization of responsibility from the provincial to the district and lower levels and association of civil society with the planning and implementation of education, including management of educational institutions, at all levels. As is dramatically illustrated by the success of many private NGOs in establishing good quality schools for the poor, there is a growing pool of businessmen, educational experts and social workers committed to the cause of education. They can play a major role in upgrading the quality of public education.

\section{Inequalities in Education}

The third structural issue is the problem of growing inequalities in the system. Inequalities in education are not confined to different literacy rates between urban and rural areas, between males and females and among different provinces. There is also a very high correlation between education and income levels. As households with higher incomes have access to better education and also to technical education, they will naturally capture a larger proportion of the employment opportunities and other benefits in a growing economy. Education inequalities are thus a major cause of growing income inequality and poverty in Pakistan.

According to a study recently conducted by SPDC, in which a District Education Index based on five educational indicators was constructed for all the Districts in Pakistan, it was found that in Punjab 14 out of 34 Districts are in the highest quintile in terms of educational facilities and only 1 in the lowest quintile. In Sindh only Karachi is in the highest quintile and two districts in the lowest, the remaining 13 districts are in the middle. In NWFP, out of 24 Districts, three are in the highest quintile and three in the lowest. But in Balochistan only one district (Quetta) out of 26 districts is in the highest quintile, and as many as 15 districts are in the lowest quintile.

It is absolutely necessary in expanding investment in education to give special attention to districts falling in the lowest quintile. The basic purpose of public spending on education should be to enhance the income earning 
capacity of the poor and education is the most important starting point for the process of social transformation leading to greater equality and social justice.

Another and more serious form of inequality springs from the strong multi dimensional divide between English medium and Urdu medium systems of education. In the recent past, this divide has been further accentuated by the rapid expansion of madrassah schools, offering religious education and catering to the educational requirements of low income groups. These three streams of education not only provide education under very different systems but also lead to divergent views and opinions about political, economic and international issues, often hostile to each other. This state of affairs, unless corrected through a more unified system of education, can lend to greater polarization in society, threatening the very unity of the federation.

\section{System of Learning and Examinations}

The fourth structural problem springs from the current system of learning and examinations in Pakistan. Based on a rigid curricula and very unexciting text books the system does not evoke the curiosity and enthusiasm of young learners. Recent research has established that the retention capacity of a child between the age of 5 and 10, when listening to a "class lecture" is no more than 10 percent. But if the class is given a practical assignment on the principle of 'learning by doing' their creativity and enthusiasm mushrooms. Independent enquiry is a critical part of learning provided the content of learning is appropriate for the age and abilities of students. There is need for a paradigm shift in the curriculum and in the teaching methodology at the primary level, if the objective of evolving an inter-disciplinary learning process that stimulates the students inherent desire to learn and his or her intellectual curiosity is to be achieved.

The quality of teachers can be improved by recruiting teachers on merit on the basis of periodical competitive examinations and by offering higher grades to teachers with higher qualifications.

Similarly, the system of examination has to move away from memorizing certain lessons for the final exam, to a more systematic assessment of understanding, reasoning, originality and creativity so that the system of teaching, learning and testing becomes an integrated process. At present the conduct of secondary and higher secondary examinations is centralized under various boards of education. Under this system the students are taught by one teacher, the examination papers are composed by another teacher, without 
knowing what has actually been taught and a third teacher marks the examination papers. There is no provision to include an assessment of the projects undertaken by the students or individual attainment of a student during the year. Examinations are largely based on text books and tend to be quite repetitive. That is why students also are not encouraged to go beyond studying (in fact memorizing) certain portions of the text books. Even laboratory experiments, a vital part of science education, are reduced to memorizing relevant passages from the lab manuals.

A gradual shift to the semester system of teaching and assessment in the system of higher education is necessary to improve the quality of education in Pakistan. The conceptual framework of the National Curriculum 2000, prepared by the National Committee, with the participation of many outside experts is a very forward looking document but its implementation has been adversely affected by recent controversies over text books and the Agha Khan Examination Board.

\section{Conclusion}

As explained above, the benefits of investment in education should not be viewed only in economic terms, these include social and political benefits, and extend from the individual to the business firm, civil society and the country as a whole.

The return on education can also be measured in different ways: monetary and non monetary, private or social:

- Private monetary returns in education are reflected in higher wages or salaries that accrue to the worker or the employee. Higher returns also encourage more students to enroll in disciplines with higher demand in the market.

- Collective or social monetary benefits of education include higher levels of human capital and skill development leading to accelerated economic growth.

- Private non-monetary benefits of education may include greater political awareness, richer cultural interactions in society and more useful intellectual contribution to the store of human knowledge.

Finally, education is the most important route to overcome unemployment and poverty. That is why the time seems ripe to incorporate in our laws the right to education as a basic human right and give investment in education the highest priority in managing the Pakistan economy. 